\title{
ALGEPS
}

REVISTA DE GEOLOGIA, SÈRIE B no 659 - Desembre del 2013

\section{RECORRIDO DESDE LIÉDANA A LUMBIER, AOIZ, BETELU, ORBAICETA Y A LOS SECTORES OCCIDENTALES DE LA SELVA DE IRATI, A TRAVÉS DEL PATRIMONIO GEOLÓGICO Y MINERO DE LAS COMARCAS DEL NORDESTE Y DEL NORTE DE NAVARRA}

Josep M. Mata-Perelló, Joaquim Sanz Balagué i Jaume Vilaltella Farràs 


\section{RECORRIDO DESDE LIÉDANA A LUMBIER, AOIZ, BETELU, ORBAICETA Y A LOS SECTORES OCCIDENTALES DE LA SELVA DE IRATI, A TRAVÉS DEL PATRIMONIO GEOLÓGICO Y MINERO DE LAS COMARCAS DEL NORDESTE Y DEL NORTE DE NAVARRA}

Por Josep M. Mata - Perelló, Joaquim Sanz Balagué y Jaume Vilaltella Farràs

\section{ADVERTENCIAS PREVIAS}

Como en otros recorridos de RECONOCIMIENTO GEOLÓGICO (o de RECONOCIMIENTO GEOLÓGICO Y MINERO), el recorrido se compondrá de diversas PARADAS. En este caso serán ocho.

Por otra parte, habrá que tener en cuenta, en todo momento, especialmente antes de empezar los recorridos de los diferentes tramos, el estado de los caminos y carreteras, por donde transitará el recorrido. Cabe indicar que posiblemente, alguna parte del recorrido se efectuará pie, por la Selva de Irati, al final del itinerario, concretamente en torno al embalse de Irabia.

Finalmente, como ya hacemos en otros recorridos similares, queremos decir que hace falta tener un cuidado muy especial en el respeto a la naturaleza, a lo largo de todo el recorrido del itinerario, y también fuera de él.

\section{BREVE INTRODUCCIÓN GEOLÓGICA}

El recorrido de este itinerario, se desarrollará por una de las dos unidades geológicas que constituyen el suelo y el subsuelo de la comunidad de Navarra / Nafarroa. Concretamente por el Sistema Pirenaico, Cordillera Pirenaica o simplemente Pirineos; discurriendo casi íntegramente por el denominado Pirineo Meridional, por los primeros tramos del recorrido. Sin embargo, en los últimos tramos entraremos en la zona afectada por el cabalgamiento de Roncesvalles, situándonos dentro de la Zona Axial Pirenaica.

Así, a lo largo de casi todo el recorrido del itinerario, se irán encontrando inicialmente afloramientos de los materiales del Cenozoico (del Eoceno y del Oligoceno), que son los que en este lugar forman parte del Pirineo. Estos materiales los encontraremos fundamentalmente entre Liédena y Aoiz.

Más adelante, a lo largo del Valle de Arce ya encontraremos afloramientos de los materiales mesozoicos, fundamentalmente del Triásico y del Cretácico. Lo mismo ocurrirá por lar cercanías de Orbaiceta. 
Asimismo, antes de llegar a Orbaiceta, habremos atravesado el Domo de OrozBetelu, encontrando afloramientos de los materiales paleozoicos del Devónico. Estos materiales los volveremos a encontrar en los tramos finales del recorrido, en las inmediaciones de la Fábrica de Orbaiceta.

\section{BREVE INTRODUCCIÓN GEOGRÁFICA}

El recorrido del presente itinerario se efectuará exclusivamente por diversos sectores de las comarcas del Nordeste y del Norte de Navarra, por el valle del río Irati, en buena parte. Así, el recorrido se iniciará en la localidad de Liédena, para desplazarse luego hacía Lumbier. Tras ello, el recorrido, remontando el río Irati, se desplazará hacía Aoiz. Desde donde se encaminará hacía las inmediaciones de Nagore. Luego, se desplazará hacía Oroz - Betelu, para llegar a Aribe y de ahí a Orbaiceta. Finalmente, llegará a los sectores occidentales de la Selva de Irati, finalizando en la Fábrica de Orbaiceta.

Como ya hemos comentado, este territorio se halla situado en la cuenca del río Irati. Este río es tributario en Lumbier, del río Salazar. Y este, en las inmediaciones de Liébana del río Aragón.

\section{OBJETIVOS GENERALES DE ESTE ITINERARIO}

En este itinerario, los objetivos generales que se han de conseguir, se pueden concretar en los siguientes aspectos:

1.- Estudio y reconocimiento de los materiales cenozoicos (fundamentalmente del Eoceno y del Oligoceno) situados en los Pirineos Meridionales, que iremos encontrando a lo largo de buena parte del recorrido, especialmente entre Liébana, Lumbier y Aoiz; así como en otros lugares del recorrido.

2.- Estudio y reconocimiento de los materiales mesozoicos (fundamentalmente pertenecientes al Cretácico y también al Triásico) situados en los Pirineos Meridionales, que iremos encontrando en diversos lugares del recorrido, como en entre Aoiz y Oroz - Betelu, por los alrededores de Orbaiceta y en otros lugares.

3.- Estudio y reconocimiento de los materiales paleozoicos (fundamentalmente pertenecientes del Devónico y del Carbonífero) situados en el Domo de Oroz-Betelu; así como en diversos sectores de la Zona Axial, que veremos en los sectores más septentrionales del recorrido.

4.- Estudio y observación de la estructura de los Pirineos, en los tramos concernientes al recorrido.

5.- Visión de algunas de las antiguas explotaciones encontradas a lo largo del recorrido del itinerario.

6.- Observación del impacto producido por las actividades mineras. Y de las restauraciones realizadas para paliar este impacto 
7.- Visión de los diferentes lugares directamente relacionados con el Patrimonio Geológico y Minero que iremos encontrando a lo largo del recorrido del presente itinerario.

8.- Observación y reconocimiento de los valores naturales de la Sierra de Irati, por donde se efectuará un recorrido a pie

\section{ANTECEDENTES BIBLIOGRÁFICOS}

En relación con este itinerario, no conocemos ningún antecedente, relativo a otro itinerario que discurra por este lugar, salvo un trabajo nuestro: MATA - PERELLÓ (2011), que discurre por territorios algo cercanos. En este sentido, estos itinerarios ya constituyen un antecedente.

Asimismo, cabe mencionar como antecedentes a diversos trabajos del IGME $(1974,1975,1978 a, 1978 b$ y 1974c).

Todos estos trabajos se hallaran debidamente relacionados en el apartado de REFERENCIAS BIBLIOGRÁFICAS, que figura al final del presente trabajo

\section{RECORRIDO DEL ITINERARIO}

El recorrido lo iniciaremos en la localidad de Liébana, por donde efectuaremos la primera parada. Esta parada será doble, frente a la Foz de Lumbier. Luego, el recorrido se encaminará hacía la población de Lumbier. En este primer tramo del recorrido, habremos circulado primero por la carretera nacional $\mathrm{N}-240$, luego la autovía A - 21; y finalmente la carretera autonómica NA - 178. Siguiendo esta última llegaremos a Lumbier.

Luego, desde esta última población, el recorrido se dirigirá hacía el Norte, siguiendo la carretera autonómica NA - 150, pasando por diversas localidades como: Rípodas, Artieda, Artajo, Aos... Poco después de esta ultima, se encontrará el cruce con la carretera NA - 135, por la que se irá hacía Aoiz. En este tramo se efectuaran dos paradas, una antes de Aoiz y la otra después.

Luego, desde Aoiz, se continuará por la carretera NA - 172, yendo hacía el Norte. Por esta carretera se entrará en el Valle de Arce, siguiendo hasta las inmediaciones del viejo pueblo de Nagore. Poco después se llegará al cruce, por la derecha, de la carretera local NA - 2040, que nos conducirá hacía el embalse de Itoiz. Al llegar a él, efectuaremos una nueva parada.

Luego, el recorrido continuará hacía el Norte, siguiendo la carretera NA - 2040. Por ella se llegará a Oroz - Betelu, Olaldea y finalmente a las inmediaciones de Ibiluzca, en donde se entroncará con la carretera NA - 140. En este tramo se efectuaran dos nuevas paradas. 
Tras ello, por la carretera NA - 150, el recorrido se dirigirá hacía Arive, desde donde se continuará hacía el Norte, por la carretera NA - 2030. Así se llegará primero a Orbara y luego a Orbaiceta. A lo largo de este recorrido se efectuará una nueva parada a la salida de Aribe.

Por esta carretera, algo más arriba de Orbaiceta, se encontrará el desvío hacía los sectores occidentales de la Selva de Irati, por donde se efectuará un recorrido. Tras ello, por la carretera anteriormente mencionada, se llegará hasta la Fábrica de Orbaiceta, por donde se efectuará la última parada del recorrido de este itinerario.

\section{DESCRIPCIÓN DEL ITINERARIO}

Como de costumbre, estructuraremos el recorrido del itinerario en una serie de PARADAS, que a continuación iremos viendo. En cada una de estas paradas haremos un breve comentario (geológico o mineralógico, según acontezca).

Por otra parte, en cada caso indicaremos (entre paréntesis) la hoja topográfica en donde se halla la parada. Para ello, utilizaremos las hojas del Instituto Geográfico y Catastral de España, publicadas a la escala de 1:50.000. En este caso, solo utilizaremos las cuatro hojas siguientes: 91 (o de Valcarlos), 116 (o de Garralda), 142 (o de Aoiz) y 174 (o de Sangüesa).

Así pues, la relación de las paradas que componen el recorrido de este itinerario, son las siguientes:

PARADA 1. FOZ DE LUMBIER - RUINAS ROMANAS, (término municipal de Liédena, comarca de Sangüesa, Merindad de Sangüesa, Navarra / Nafarroa). (Hoja 174).

El recorrido lo iniciaremos en la población de Liédena, tomando hacía el Oeste la carretera nacional $\mathrm{N}-240$. Tras un corto recorrido de unos $3 \mathrm{Km}$, llegaremos a la rotonda de entrada a la autovía A - 21. Sin embargo, convendrá tomar la vía de servicio septentrional que conduce a las Ruinas Romanas de Liédena. Al llegar efectuaremos una doble parada: en las ruinas y a unos 100 metros, para ver la salida del río Salazar - Irati, por la Foz de Lumbier.

En este recorrido, habremos circulado entre los materiales cenozoicos del extremo occidental de la Canal de Berdún y los materiales también cenozoicos (y mesozoicos) del extremo occidental de la Sierra de Leyre. Cabe indicar que ambos elementos se sitúan dentro del Pirineo Meridional.

Por una parte, en este lugar pueden observarse las ruinas de la antigua Liébana, con varias excavaciones (FOTOGRAFÍA 1). Y por otra puede verse la salida de la Foz de Lumbier, atravesada por el río Salazar - Irati (FOTOGRAFÍA 2). Así, puede verse como este río se abre paso entre los afloramientos carbonatados mesozoicos, y como el río cambia su trayectoria $\mathrm{N}-\mathrm{S}$, para tomar una dirección $\mathrm{O}-\mathrm{E}$, al entrar en los sectores occidentales de la Canal de Berdún, para encaminarse hacía el río Aragón, en el que desembocará entre Liédena y Sangüesa. 


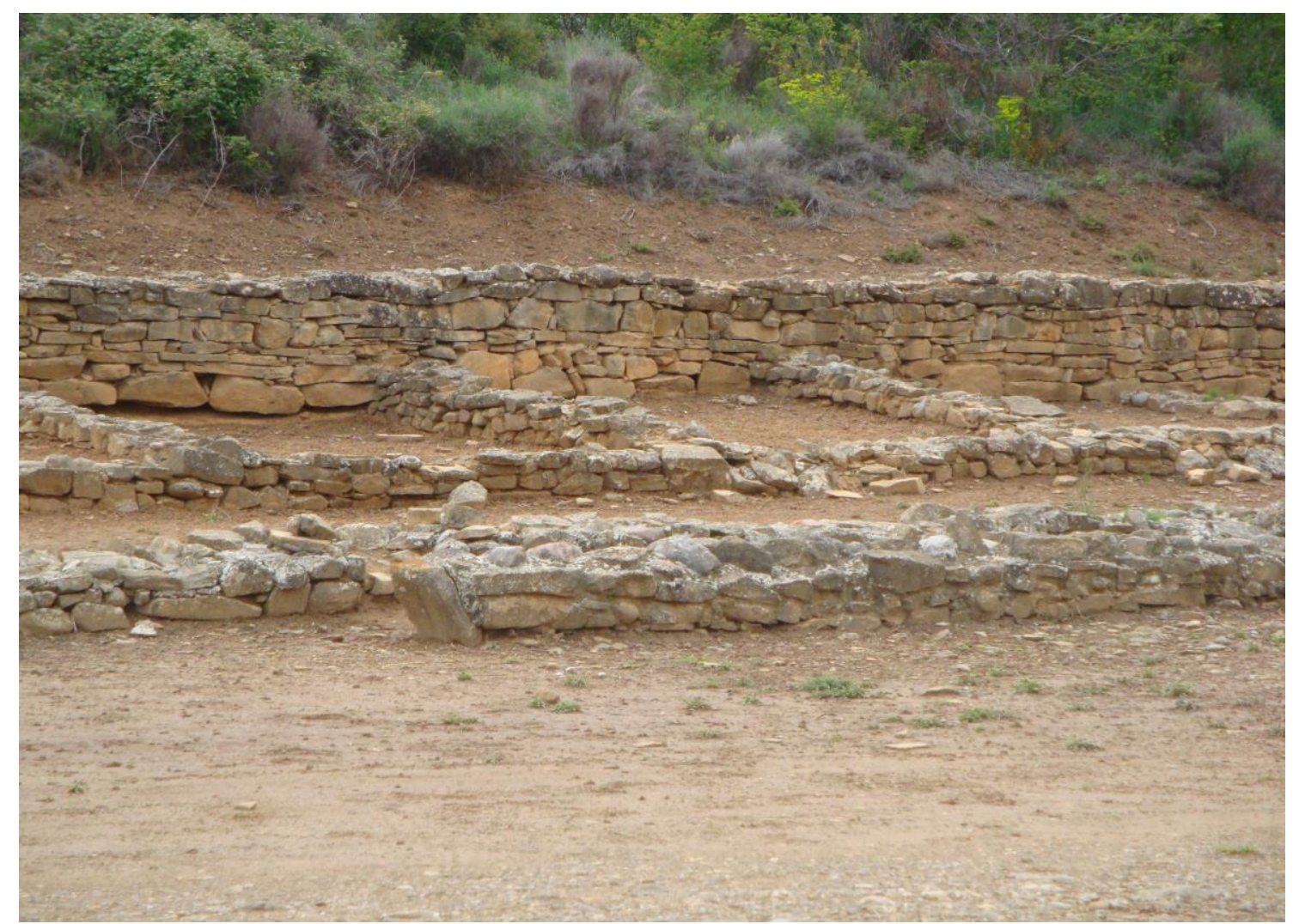

FOTOGRAFÍA 1

Aspecto de las excavaciones de las ruinas romanas de Liébana

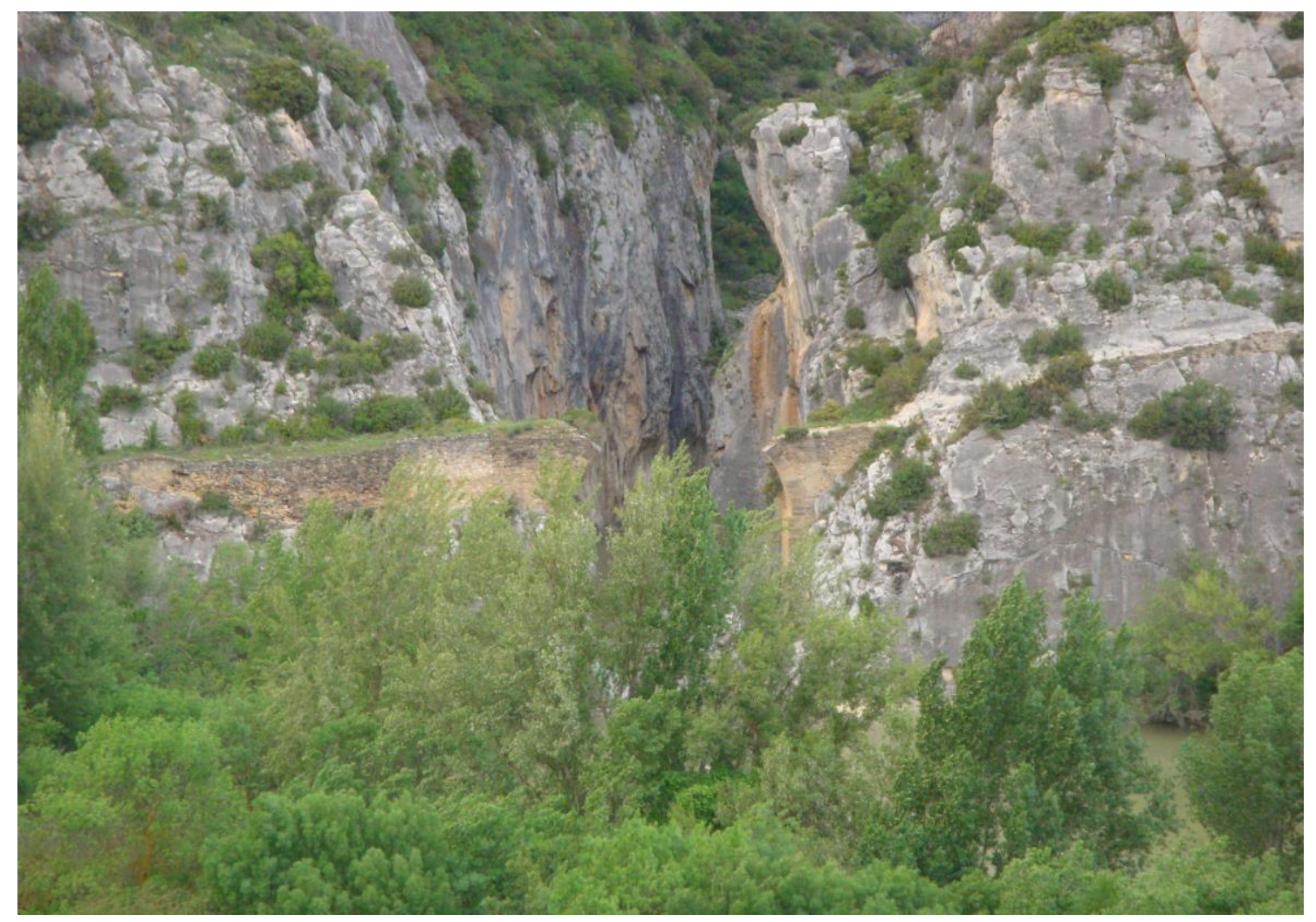

FOTOGRAFÍA 2

Salida de la Foz de Lumbier y cambio de dirección del río Salazar - Irati 
PARADA 2 - CONDICIONAL. INMEDIACIONES DE ARTIEDA, (Artieda, municipio de Urral Bajo, comarca de Lumbier, Merindad de Sangüesa, Navarra / Nafarroa). (Hoja 142).

Después de realizar la parada anterior, conviene continuar hacía Lumbier, tomando ahora la autovía A - 21 y luego la carretera NA - 178. Al llegar a esta última población, nos convendrá seguir hacía el Norte por la carretera autonómica NA - 150, pasando por diversas localidades como: Rípodas y Artieda. Al llegar a las inmediaciones de esta última población, podemos efectuar una nueva parada, a unos 12 $\mathrm{Km}$ de la anterior.

A lo largo del recorrido, desde Lumbier hasta el lugar de la parada, iremos circulando por el valle del río Irati, entre afloramientos de los materiales cenozoicos del Eoceno, pertenecientes al Pirineo Meridional. Antes, sin embargo, cerca de Lumbier, habremos cortado el extremo meridional de la Sierra de Leyre.

Asimismo, en este trayecto, al pasar por las inmediaciones de Lumbier, habremos pasado cerca de la confluencia de los ríos Irati y Salazar.

Desde el lugar de la parada, puede efectuarse una observación del valle del río Irati, por donde hemos estado circulando. FOTOGRAFÍA 3

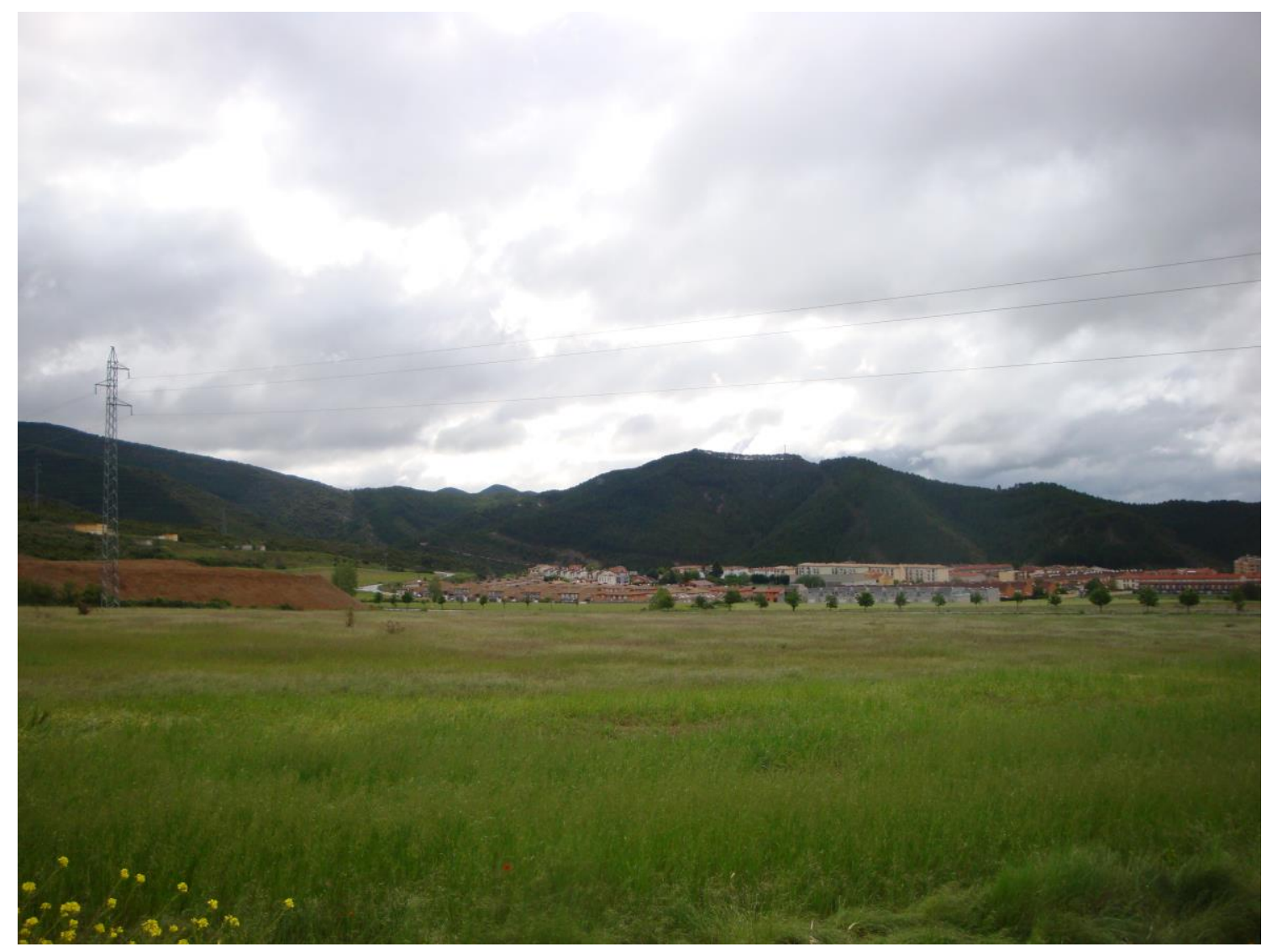

FOTOGRAFÍA 3

Valle del río Irati, cerca de Artieda 
PARADA 3. SALIDA DE AOIZ POR LA CARRETERA NA - 172, (término municipal de Aoiz / Agoitz, comarca de Agoiz, Merindad de Sangüesa, Navarra / Nafarroa). (Hoja 142).

Una vez realizada la parada anterior, será necesario continuar hacía el Norte por la carretera NA - 150, pasando por las inmediaciones de Artajo y de Aos. Tras dejar este pueblo, se encontrará el cruce con la carretera NA - 135, por la que se irá hacía Aoiz. Luego, desde Aoiz, se continuará por la carretera NA - 172, yendo hacía el Norte. Sin embargo, a la salida de Aoiz, efectuaremos una nueva parada, tras recorrer unos $12 \mathrm{Km}$ desde la anterior.

En este recorrido, habremos ido cortando afloramientos de los materiales cenozoicos mencionados en las paradas anteriores. Estos materiales pertenecen al Eoceno y forman parte del Pirineo Meridional, en donde estamos situados.

Desde este lugar, junto a la carretera, pueden verse unos releves, que forman parte de un frente de cabalgamiento de dirección OSO - ENE. Ello puede observarse, ligeramente en la FOTOGRAFÍA 4. Cabe decir que estos releves constituyen la Peña de Santa Bárbara, en donde también afloran los materiales cenozoicos, en este caso más detríticos.



FOTOGRAFÍA 4

Relieves cenozoicos de la Peña de Santa Bárbara 
PARADA 4. EMBALSE DE ITOIZ, (Lacabe / Lakabe, término municipal de Arce / Artzi, comarca de Auñamendi, Merindad de Sangüesa, Navarra / Nafarroa). (Hoja 116).

Una vez realizada la parada anterior, será necesario continuar hacía el Norte por la carretera NA - 135. Por esta ruta se entrará en el Valle de Arce, siguiendo hasta las inmediaciones del viejo pueblo de Nagore. Poco después se llegará al cruce, por la derecha, de la carretera local NA - 2040, que nos conducirá hacía el embalse de Itoiz. Al llegar a él, efectuaremos una nueva parada, junto al mencionado embalse. Así, desde la parada anterior, habremos recorrido unos $15 \mathrm{Km}$.

En este recorrido habremos empezado a encontrar afloramientos de los materiales cenozoicos mencionados en las paradas anteriores. Sin embargo, ahora, en el lugar de la presente parada, habremos visto unos afloramientos de calizas mesozoicas del Cretácico. En ambos casos, nos hallamos situados en el Pirineo Meridional; aunque los afloramientos mesozoicos que ahora vemos, se hallan afectados por la reactivación tectónica del domo de Oroz-Betelu, que más adelante cortaremos.

Así, en este lugar pueden observarse unas interesantes fracturas, de dirección ONO - ESE, que afectan a las calizas cretácicas. Así, los espejos de falla son muy ostensibles. FOTOGRAFÍAS 5 y 6.

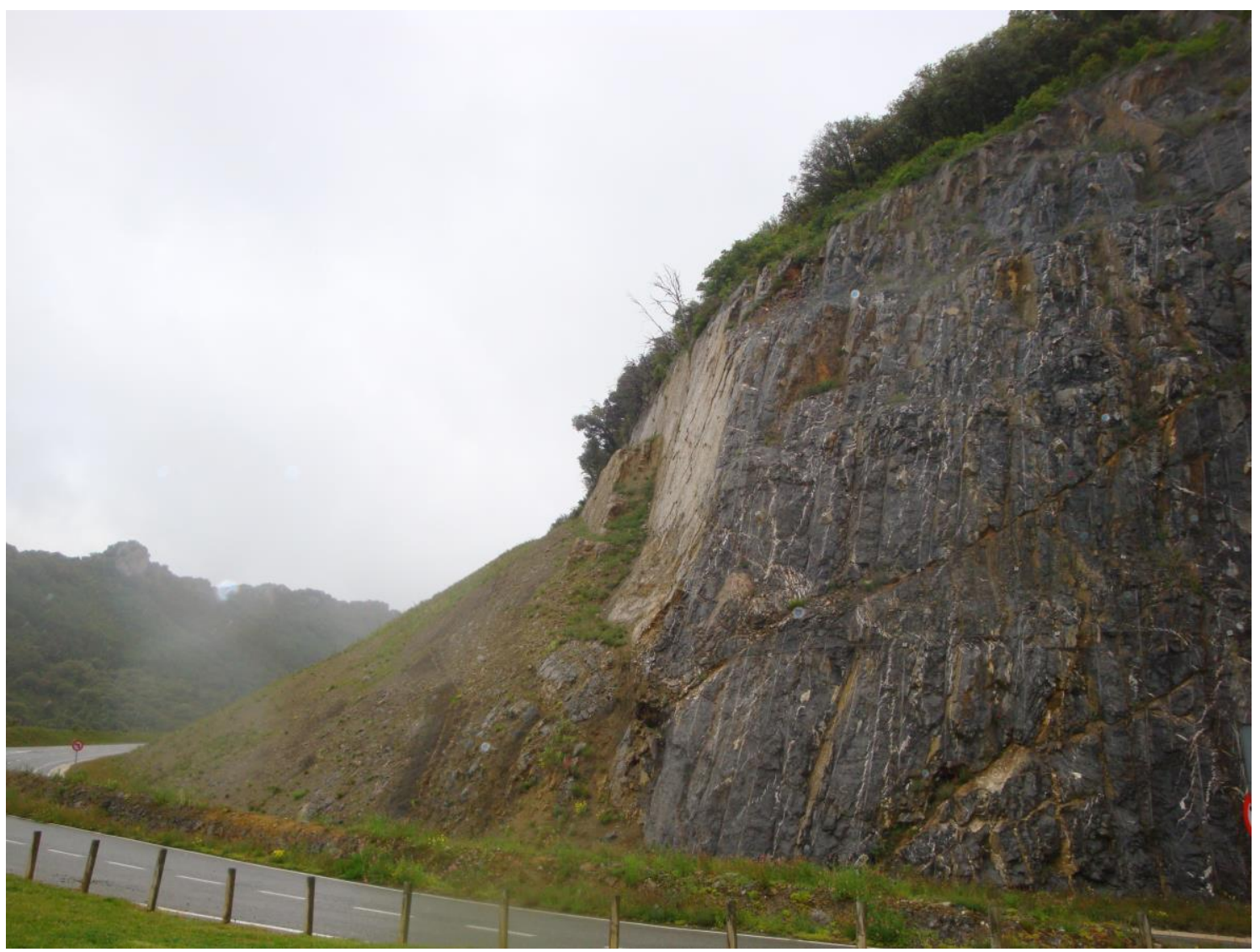

FOTOGRAFÍA 5

Fracturas y espejos de falla, junto al embalse de Itoiz 


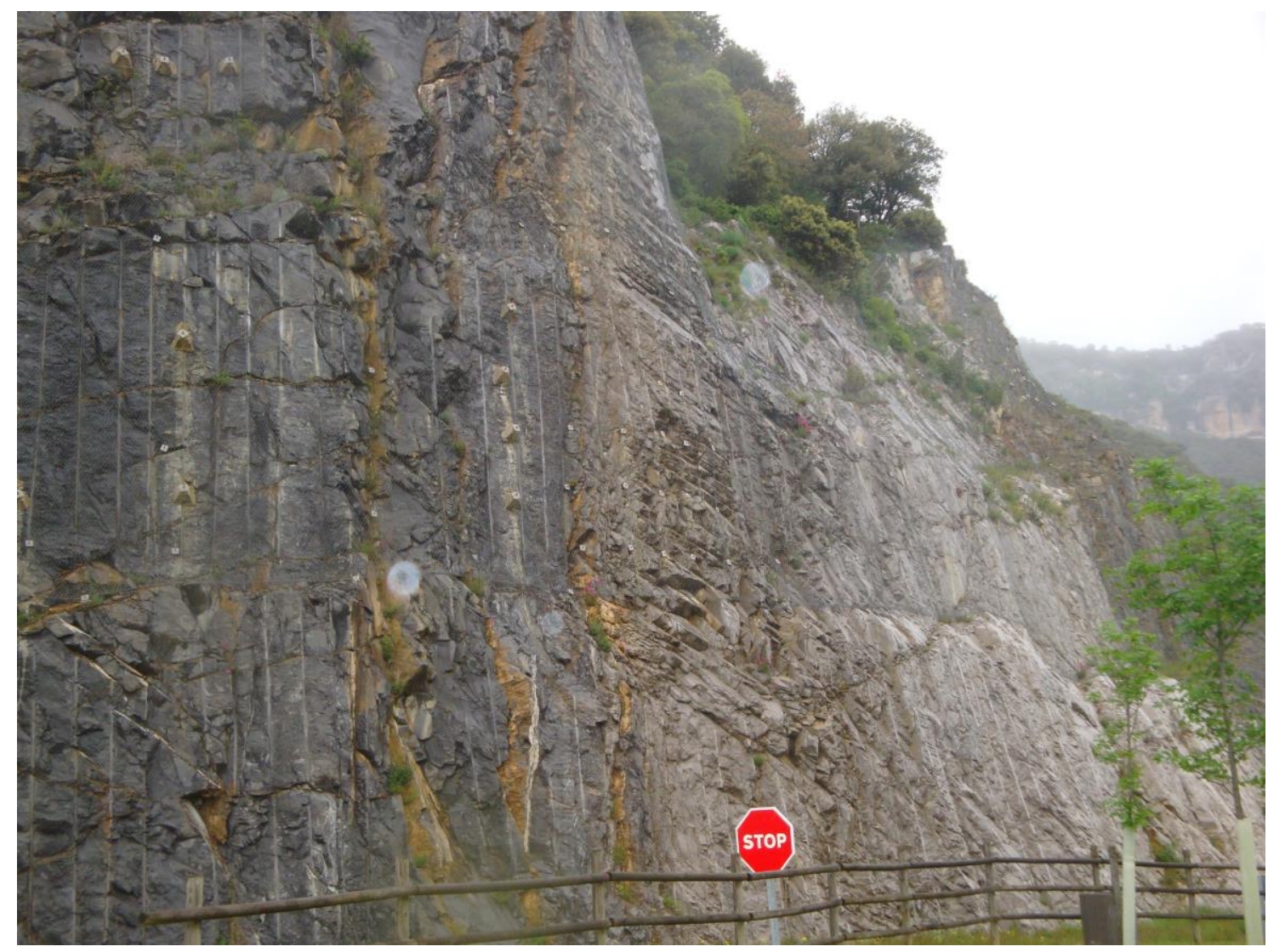

FOTOGRAFÍA 6

Un aspecto más de las estructuras anteriores

PARADA 5 - CONDICIONAL. INMEDIACIONES DE OROZ BETELU, CARRETERA NA - 2040, (término municipal de Oroz - Betelu / Orotz - Betelu, comarca de Auñamendi, Merindad de Sangüesa, Navarra / Nafarroa). (Hoja 116).

Tras efectuar la parada anterior, conviene continuar hacía el Norte, por la carretera NA - 2040. Siguiéndola llegaremos pronto a la población de Oroz - Betelu. Tras sobrepasarla, efectuaremos una nueva parada, entre esta población y la de Olaldea. Así, desde la parada anterior, habremos recorrido unos $6 \mathrm{Km}$.

En este recorrido habremos ido encontrando afloramientos de los materiales mesozoicos citados anteriormente. En principio, habremos ido encontrando niveles carbonatados calcáreos cretácicos. Más adelante, habremos sobrepasado niveles carbonatados del Muschelkalk (del Triásico Medio). Y, finalmente, más adelante en este recorrido, habremos visto niveles de las areniscas rojas del Buntsandsteim, del Triásico Inferior. Estos son los materiales que afloran en el lugar de la parada, en donde hubo una canterita.

Conviene indicar que en este trayecto, nos habremos adentrado en el domo de Oroz - Betelu, del que ya hemos hablado en la parada anterior. Se trata de una estructura pirenaica, prehercínica, reactivada durante el plegamiento alpino. 
PARADA 6 - CONDICIONAL. INMEDIACIONES DE ORALDEA, CARRETERA NA - 2040, (Olaldea, término municipal de Oroz - Betelu / Orotz - Betelu, comarca de Auñamendi, Merindad de Sangüesa, Navarra / Nafarroa). (Hoja 116).

Después de efectuar la parada anterior, conviene continuar hacía el Norte, por la carretera NA - 2040, con la finalidad de llegar al pueblo de Olaldea. Al llegar a las inmediaciones del mismo, efectuaremos una nueva parada, a unos $3 \mathrm{Km}$ de la anterior.

En este recorrido, habremos estado circulando entre los afloramientos mesozoicos del domo de Oroz - Betelu. Sin embargo, en las inmediaciones de donde estamos ahora, habremos encontrado afloramientos paleozoicos pertenecientes al Devónico. Se trata de niveles de esquistos y de calizas, fundamentalmente. Así, pues, estos son los materiales que afloran en el lugar de la presente parada.

PARADA 7 - CODICIONAL. CONGOSTO DE ARIVE DEL RÍO IRATI, CARRETERA NA - 2030, (término municipal de Arive / Aribe, comarca de Auñamendi, Valle de Aézcoa, Merindad de Sangüesa, Navarra / Nafarroa). (Hoja 116).

Desde la población de Oraldea, conviene continuar hacía el Norte por la carretera NA - 2040, con la finalidad de llegar a las inmediaciones de Ibiluzca, en donde se entroncará con la carretera NA - 140. Desde ahí, convendrá seguir por la carretera acabada de encontrar, hacía el pueblo de Arive. Luego, dentro de la población, nos convendrá seguir por la carretera NA - 2030, para efectuar una parada a la salida de la población, si se da el caso. Así, habremos efectuado un recorrido de unos $7 \mathrm{Km}$ más.

En este recorrido, habremos circulado entre los afloramientos paleozoicos del Devónico, hasta las inmediaciones de Arive. Luego, habremos vuelto a encontrar los materiales triásicos (del Buntsandsteim y del Muschelkalk). Y finalmente, al llegar a Arive, habremos encontrado afloramientos de os materiales carbonatados cretácicos. Es decir, a lo largo de este recorrido, habremos atravesado el domo de Oroz-Betelu. Sin embargo, en el lugar de la parada aparecen unos niveles carbonatados eocénicos.

PARADA 8. SECTORES OCCIDENTALES DE LA SELVA DE IRATI. EMBALSE DE IRABIA, (término municipal de Orbaiceta / Orbaitzeta, comarca de Auñamendi, Valle de Aézcoa, Merindad de Sangüesa, Navarra / Nafarroa). (Hoja 116).

Tras realizar la parada anterior, convendrá continuar hacía el Norte, por la carretera NA - 2030 que hemos tomado en Arive. Por esta carretera llegaremos pronto a las poblaciones de Orbara y Orbaiceta. Poco después de esta última, nos convendrá tomar el ramal que conduce al Embalse de Irabia, dentro de los sectores occidentales de la Selva de Irati. Al llegar ahí, efectuaremos una nueva parada, tras un recorrido aproximado de unos $19 \mathrm{Km}$, unos 13 desde Orbaiceta. 


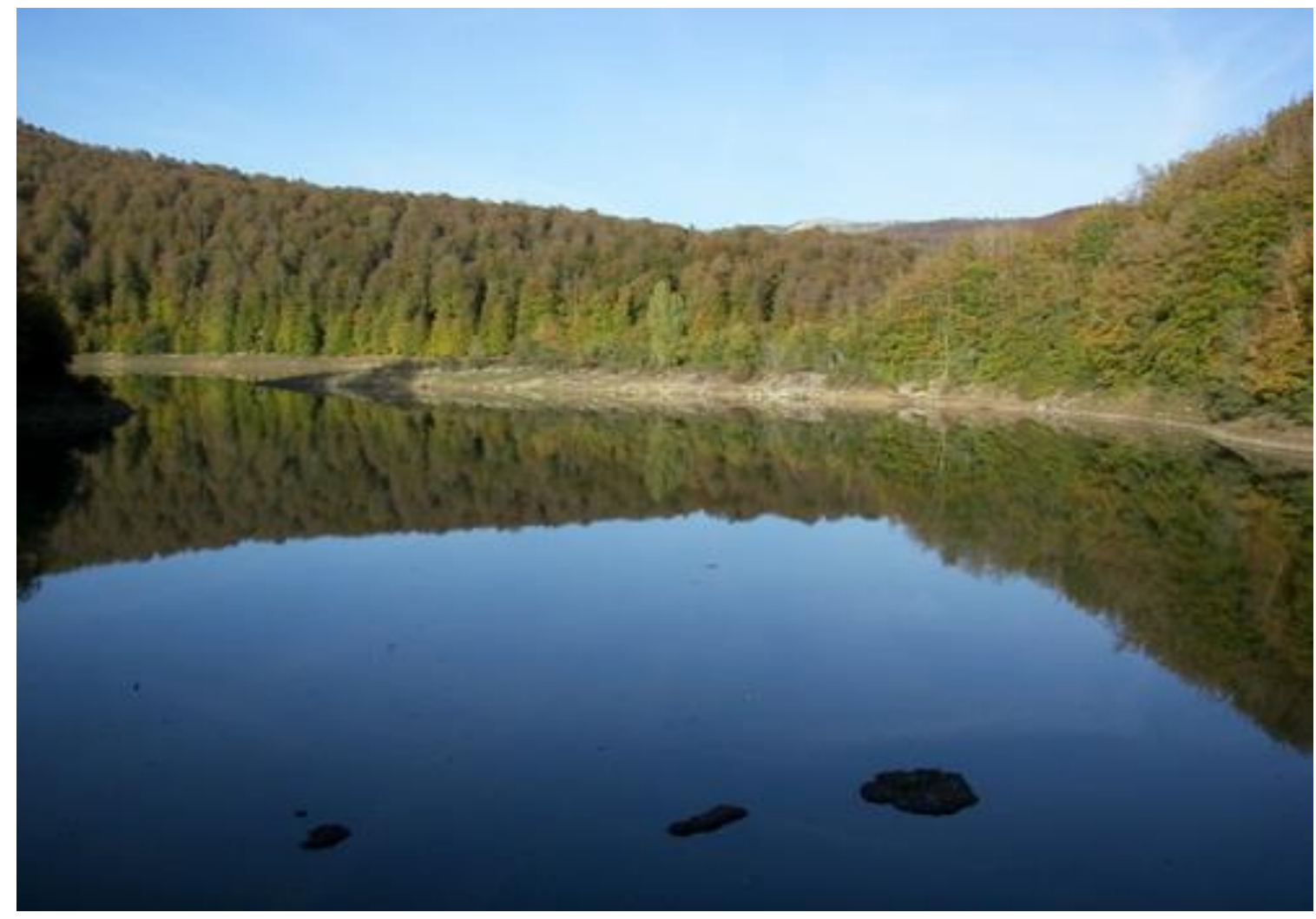

FOTOGRAFÍA 7

Un aspecto del embalse de Iratia en la Selva de Irati, extraída de INTERNET

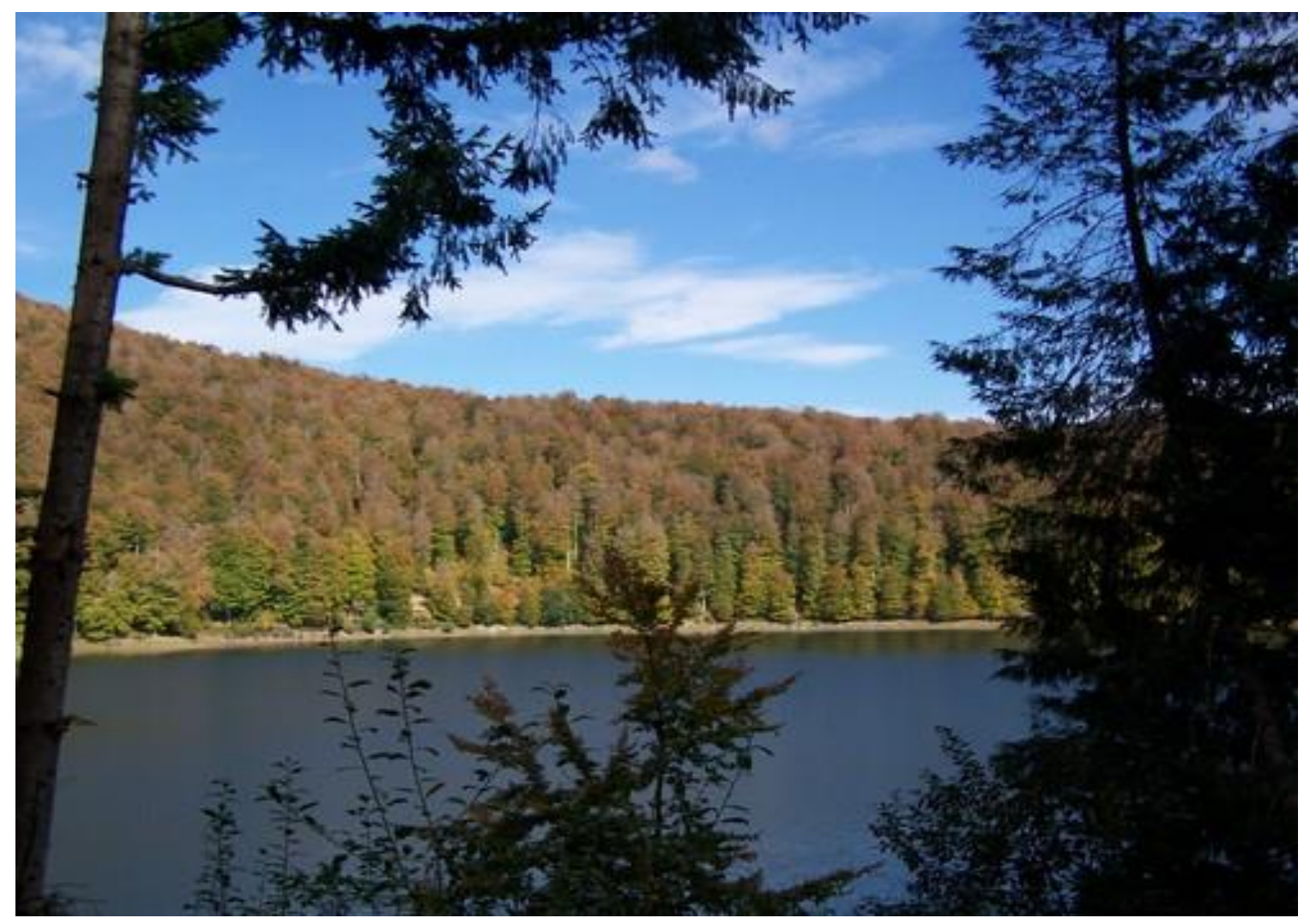

FOTOGRAFÍA 8

Otro aspecto del embalse de Iratia en la Selva de Irati, extraída de INTERNET 
Al llegar al embalse de Irabia, lo que recomendamos es efectuar un recorrido a pie, contorneándolo. Así podremos apreciar mejor las características de la Selva de Irati, por estos contornos, observando los magníficos bosques de hayedos y de abetos, constituyendo la mayor masa forestal de Navarra, repartiéndose entre la Alta y la Baja Navarra, Dentro de este recorrido, podremos efectuar diversas alternativas-

Por otra parte en este recorrido, habremos vuelto a encontrar afloramientos de los materiales mesozoicos cretácicos, de los que hemos hablado en otras paradas. Posteriormente, habremos visto afloramientos de los materiales cenozoicos del Eoceno, situándose unos y otros dentro del Pirineo Meridional. Sin embargo, en el lugar de la parada, encontraremos afloramientos mesozoicos del Cretácico y cenozoicos del Eoceno, según los sectores del embalse de Irabia. FOTOGRAFÍAS 7 y 8 (extraídas de INTERNET)

PARADA 9. FÁBRICA DE ARMAS DE ORBAICETA, (término municipal de Orbaiceta / Orbaitzeta, comarca de Auñamendi, Valle de Aézcoa, Merindad de Sangüesa, Navarra / Nafarroa). (Hoja 116).

Después de efectuar la parada anterior, nos convendrá retroceder hasta las inmediaciones del pueblo de Orbaiceta, para continuar des ahí hacía el Norte, de nuevo por la carretera NA - 2030. Así llegaremos a la antigua Fábrica de Armas de Orbaiceta, en donde podemos efectuar la última parada del recorrido de este itinerario. Así, desde la parada anterior, habremos recorrido unos $15 \mathrm{Km}$, aproximadamente.

Cabe la posibilidad de efectuar este recorrido a pie, aunque con menos distancia, para ello, desde el embalse de Iratia, convendrá seguir el viejo trazado del sendero pirenaico GR - 11, que conducía desde el mencionado embalse hasta los restos de la fábrica de armas.

En este recorrido, habremos ido encontrando afloramientos de los materiales mencionados en la parada anterior. Así, en las inmediaciones de la fábrica afloran los materiales cenozoicos eocénicos del Eoceno. Sin embargo, al norte de la misma, en las cercanías de Sayarre y Orculo, ya afloran los materiales paleozoicos de la Zona Axial Pirenaica. Se trata de afloramientos de los materiales Devónicos y Carboníferos, fundamentalmente.

Por lo que acontece en relación con la Real Fábrica de Armas de Orbaiceta, cabe decir que se trata de los restos de un importante establecimiento militar, que solo estuvo en funcionamiento durante unos 100 años, entre 1784 y 1884. Esta fábrica se instaló en los terrenos de una antigua ferrería (la Ferrería de Aézcoa) en la que se aprovechaban los minerales de hierro extraídos entre los afloramientos devónicos situados al Norte de la actual fábrica.

Cabe indicar que junto a los restos de la fábrica, existe el viejo poblado (actualmente habitado), entre el que destacan algunas de las viviendas, así como la iglesia, utilizada a menudo como aparcamiento.

Es interesante efectuar una visita por los antiguos restos, aunque tomando las debidas precauciones, dado el estado ruinoso. FOTOGRAFÍA 9. 


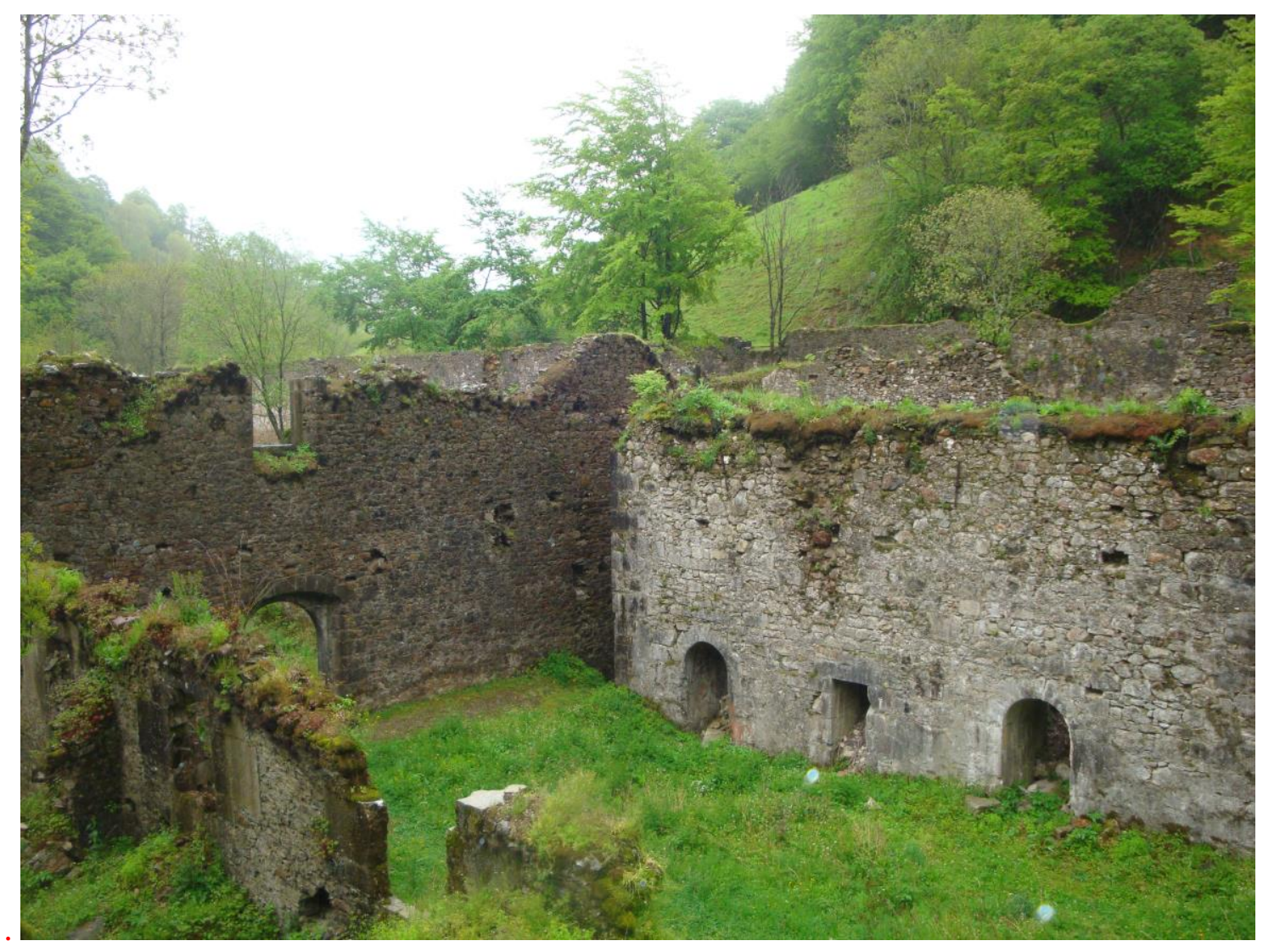

FOTOGRAFÍA 9

Restos de la Real Fárica de Armas de Orbaiceta (1784 - 1884)

\section{EN ESTE LUGAR FINALIZA EL RECORRIDO}

\section{BIBLIOGRAFIA}

IGME (1974).- Mapa Geológico de España, a escala 1:200.000, Síntesis de la Cartografía existente. Hoja y explicación de la misma, $\mathrm{n}^{\circ} 13$ (Pamplona). Inst. Geol. Min. España. Ministerio de Industria. Madrid

IGME (1975).- Mapa de Rocas Industriales de España, a escala 1:200.000. Hoja y explicación de la misma, no 13 (Pamplona). Inst. Geol. Min. España. Ministerio de Industria. Madrid

IGME (1978a).- Mapa Geológico de España, a escala 1:50.000. Hoja y explicación de la misma, números: 116 (Garralda). Inst. Geol. Min. España. Ministerio de Industria. Madrid

IGME (1978b).- Mapa Geológico de España, a escala 1:50.000. Hoja y explicación de la misma, números: 142 (Aoiz). Inst. Geol. Min. España. Ministerio de Industria. Madrid

IGME (1978c).- Mapa Geológico de España, a escala 1:50.000. Hoja y explicación de la misma, números: 174 (Sangüesa). Inst. Geol. Min. España. Ministerio de Industria. Madrid 
MATA-PERELLÓ, J.M. (2011).- Recorrido desde Salvatierra de Esca a la Piedra de San Martín, a través del patrimonio geológico y minero de la comarca de la Jacetánia y del Valle del Roncal. Inédito. 10 páginas. Manresa 